\title{
Pain evoked by electrical stimulation of the prepyloric region of the stomach: Cutaneous sensibility changes in the referred pain area
}

\author{
Asbjørn M Drewes MD PhD ${ }^{1,2}$, Henrik B Krarup MD ${ }^{1}$, Jesper B Hansen $\mathrm{MD}^{1}$, Ulrik Tage-Jensen MD PhD ${ }^{1}$, \\ Lars Arendt-Nielsen MSci PhD ${ }^{2}$
}

AM Drewes, HB Krarup, JB Hansen, U Tage-Jensen, L Arendt-Nielsen. Pain evoked by electrical stimulation of the prepyloric region of the stomach: Cutaneous sensibility changes in the referred pain area.

Pain Res Manage 1999;4(3):131-137.

OBJECTIVE: To investigate the pain threshold and the referred pain areas to electrical stimulation of the prepyloric region of the stomach, and the cutaneous sensibility in the referred pain areas. DESIGN: Eight healthy males volunteered for the study. To identify the area of referred pain, all subjects participated in a study using the same model four months previously. During gastroscopy, repeated electrical burst stimuli were delivered in four adjacent prepyloric sites of the stomach, and the pain detection thresholds (PDTs) together with the area of pain referral were determined. Before, during and after continuous electrical painful stimuli delivered in the prepyloric region, the cutaneous sensitivities in the referred pain area and a control area on the chest were characterized using electrical, heat, touch and pinprick stimuli.

RESULTS: The PDTs in the four prepyloric areas were not different and the location of the referred pain was reproducible. During the nociceptive visceral stimuli, hyperalgesia to heat stimulation was detected in the referred pain area compared with the control area, but the thresholds for electrical, touch and pinprick stimulations did not change.

CONCLUSIONS: The reproducible pain thresholds in adjacent prepyloric sites make future analysis in patient groups possible because the precise site of stimulation can vary without changing the sensibility. The modality-specific somatosensory changes in the referred pain areas further indicate that visceral pain can cause differentiated sensory changes. Modality-specific sensibility changes are also seen in referred areas to muscle pain. Thus, the model may increase the information on viscerocutaneous convergence phenomena in humans.

Key Words: Experimental pain; Referred pain; Sensation; Stomach

\section{Douleur déclenchée par une stimulation électrique de la partie de l'estomac située en amont du pylore : changements dans la sensibilité cutanée dans la zone de douleur référée}

OBJECTIF : Examiner le seuil de la douleur et les zones de douleur référée à une stimulation électrique de la partie de l'estomac située en amont du pylore, et la sensibilité cutanée dans les zones de douleur référée.

MODÈLE : Huit hommes en bonne santé se sont portés volontaires pour cette étude. Pour identifier la zone de la douleur référée, tous les sujets avaient participé à une étude faisant appel au même modèle quatre mois auparavant. Pendant la gastroscopie, des stimuli répétés de décharges électriques ont été envoyés dans quatre sites adjacents de l'estomac situés en amont du pylore puis, les seuils de détection de la

\footnotetext{
${ }^{1}$ Department of Medical Gastroenterology, Aalborg Hospital, ${ }^{2}$ Laboratory for Experimental Pain Research, Center for Sensory-Motor Interaction, Aalborg University, Aalborg, Denmark

Correspondence and reprints: Dr Asbjørn Mohr Drewes, Department of Medical Gastroenterology, Aalborg Hospital, DK-9000 Aalborg, Denmark. Telephone +45 99322499, fax +45 99322503, e-mail drewcs@aas.nja.dk

Received for publication February 16, 1999. Accepted March 4, 1999.
} 
douleur ainsi que la zone de douleur référée ont été déterminés. Avant, après et pendant les stimuli électriques douloureux, envoyés de façon continue dans la région située en amont du pylore, les sensibilités cutanées dans la zone de douleur référée et dans une zone témoin située dans la poitrine ont été caractérisées à l'aide de stimuli électriques, de la chaleur, par le toucher ou avec des piqûres d'épingle.

RÉSULTATS : Les seuils de détection de la douleur dans les quatre zones situées en amont du pylore n'étaient pas différents et le site de la douleur référée était reproductible. Pendant les stimuli nociceptifs dans les viscères, une hyperalgésie à la stimulation par la chaleur a été décelée dans la zone de la douleur référée comparativement à la zone témoin, mais les seuils obtenus lors des stimulations électriques, tactiles et à la piqûre d'épingle n'ont pas varié.

CONCLUSIONS : Les seuils reproductibles de la douleur dans des zones adjacentes situées en amont du pylore permettront de procéder à d'autres analyses dans des groupes de patients, car le site précis de la stimulation peut varier sans modifier la sensibilité. Les changements somatosensoriels spécifiques à la modalité dans les zones de douleur référée indiquent que la douleur viscérale peut provoquer des changements sensoriels différenciés. De plus, les changements de sensibilité spécifiques à la modalité sont aussi observés dans les zones de douleur référée d'origine musculaire. Ainsi, ce modèle peut
A bdominal pain and discomfort are among the most common symptoms responsible for patients seeking the care of a gastroenterologist $(1,2)$. Diseases such as peptic ulcer are frequently located in the prepyloric region of the stomach, especially in patients on long term treatment with nonsteroidal anti-inflammatory drugs (3). Better knowledge of basic pain mechanisms related to this area is, therefore, of major clinical importance. In the clinic, gastric pain is difficult to assess due to great intraindividual variability in the intensity and localization of deep referred pain as well as adjacent sensory phenomena. Due to the complexity of the symptoms in clinical pain, experimental models are needed where localized and standardized pain stimuli can be delivered. Experimental studies can be used to investigate basic physiological mechanisms of nociceptive processing related to the human stomach. Most experimental models are based on distension of the gut wall using balloons. In the stomach, such diseases as peptic ulcer are, however, more localized and poorly mimicked by the distension models. Therefore, we used a previously developed model through which localized, painful electrical stimuli can be delivered to specific sites of the gastric mucosa during simultaneous visual inspection through the gastroscope (4). The electrical stimuli can be delivered with different intensities and sequences permitting the study of visceral pain reactions to graded stimuli. More data are needed, however, regarding the validity of the electrical model, especially for stimulation in the prepyloric region. Visceral pain is often referred to a somatic area, typically in the skin, due to direct or indirect convergence of nerve fibres from visceral and somatic tissue at a peripheral or central level (5). Information regarding sensibility in the referred pain area during visceral pain may increase our knowledge of such convergence mechanisms and the central mechanisms involved in the generation and maintenance of visceral pain. Experimental studies in animals have shown diverging results in the somatic nervous system following visceral stimuli $(6,7)$. In human studies, somatosensory changes in the referred pain areas following visceral and deep somatic nociceptive stimuli are contoversial. Thus, in clinical studies, hyperalgesia of the skin has been reported in visceral pain conditions (8-10). In other deep tissues such as the muscle, however, sensitivity changes in the referred pain areas have been shown to be modality dependent (11-13).
Because electrical stimulation has previously been used to elicit visceral pain with referral to the skin, this method seems to be valuable to study aspects of viscerosomatic convergence. The present study was conducted to investigate the pain sensibility to electrical stimuli applied in different prepyloric sites and to study the modality-specific sensibility changes in the referred pain area.

\section{Subjects}

\section{PATIENTS AND METHODS}

Of 12 subjects who participated in a previous experiment using the same stimuli (4), eight volunteered to enter the present study. The eight subjects were healthy men 20 to 25 years of age. All received compensation for their assistance. Subjects had no previous history of gastrointestinal disease. The study was conducted according to the Helsinki Declaration and approved by the local ethics committee.

\section{Protocol}

A venous line was established, and pulse and blood pressure were continuously monitored using Pro-paq102 (Protocol Systems Inc, Beaverton, Oregon). The subjects fasted for $8 \mathrm{~h}$ and underwent gastroscopy using the Olympus GIF-100 endoscope(Olympus Optica Co, Hamburg, Germany) with minimal air insufflation and without any medication. When subjects were comfortable with the gastroscope, the stimulator, described in detail below, was inserted into the biopsy channel and pressed firmly against the mucosa (Figure1).

Experiment 1: The pain detection thresholds (PDTs) to 'repeated electrical burst stimuli' were found in four prepyloric areas. Positions 1 to 3 were at the bottom, left and right sites; respectively, of the prepyloric area, approximately $10 \mathrm{~mm}$ proximal to the pylorus. Position 4 was $10 \mathrm{~mm}$ proximal to position 1 at the bottom of the stomach. Subjects were told to indicate on a standardized drawing of a human body where they felt pain.

The location and size of the referred pain following the electrical stimuli were compared with the findings of the previous experiment (4).

Experiment 2: From the pilot experiments, it was suspected that the area of referred pain would be in the region previously located in each subject. Therefore, before any pain was 
stimulated in the stomach, the cutaneous pain thresholds to electrical stimuli were found. The stimulus- response (S-R) function to electrical stimuli in the cutaneous area where the referred pain was suspected to be was also located. Details on the cutaneous electrical, thermal and mechanical stimuli are discussed below. The same measurements were performed in a corresponding control area at the upper right side of the chest. In the same two areas in each subject, the pain intensity following thermal stimuli was rated, and the mechanical sensations in the two areas were compared. All measurements were determined again during and after continuous electrical pain stimuli in the prepyloric area. The electrical pain stimuli was applied at position 1 in the bottom of the prepyloric region.

\section{Electrical stimulation of the stomach}

Stimulating electrodes (platinum balls with a $1 \mathrm{~mm}$ diameter) were embedded into a plastic coating and mounted on biopsy forceps for the gastroscope. During stimuli the forceps were opened, leaving $4 \mathrm{~mm}$ between the electrodes, and pressed lightly against the mucosa (Figure 1). Teflon-coated stainless steel wires were used to deliver bipolar stimuli by a computer-controlled constant current stimulator (Aalborg University, Aalborg, Denmark). 'Single burst stimulus' consisted of a train of five $1 \mathrm{~ms}$, rectangular pulses given at $200 \mathrm{~Hz}$. 'Repeated burst stimulus' consisted of five single burst stimuli given at $2 \mathrm{~Hz}$. For 'continuous stimulus', the single burst stimuli were delivered at $4 \mathrm{~Hz}$. For the intragastric stimuli, only repeated burst and continuous stimuli were used for the investigations. Previous experience showed that repeated burst stimuli are most reliable for gastric pain threshold measurements, whereas continuous stimuli are the best to elicit referred pain for longer durations (4). Continuous stimulation has the same effect as single and repeated stimuli, although the pain intensity may vary during the experiment (4). During the pain threshold measurements in the stomach, the current was gradually increased in 0.5 to 1 $\mathrm{mA}$ increments by using repeated burst stimuli, and the sensation was reported simultaneously. Subjects indicated when they felt that the sensation became painful. Accordingly, the PDT was reached when the subject indicated that the sensation changed from a nonpainful sensation to one of severe unpleasantness.

For the continuous stimulation, a current intensity corresponding to approximately $3 \mathrm{~cm}$ on an electronic visual analogue scale (VAS) ranging from 0 (no pain) to 10 (unbearable pain), was determined during $10 \mathrm{~s}$ test stimuli. This intensity was given in the subsequent experiment where pain was elicited for approximately 5 to 10 mins. If pain increased above 7 on the VAS during the session, the stimulation was stopped. Furthermore, the subject could activate a stop button at any time during the experiment.

\section{Electrocutaneous stimulation}

A stimulation probe (Dantec 13L35, Copenhagen, Denmark) with saline-soaked felt tips was placed on the skin in the referred pain area and in the control area $10 \mathrm{~mm}$ apart. The

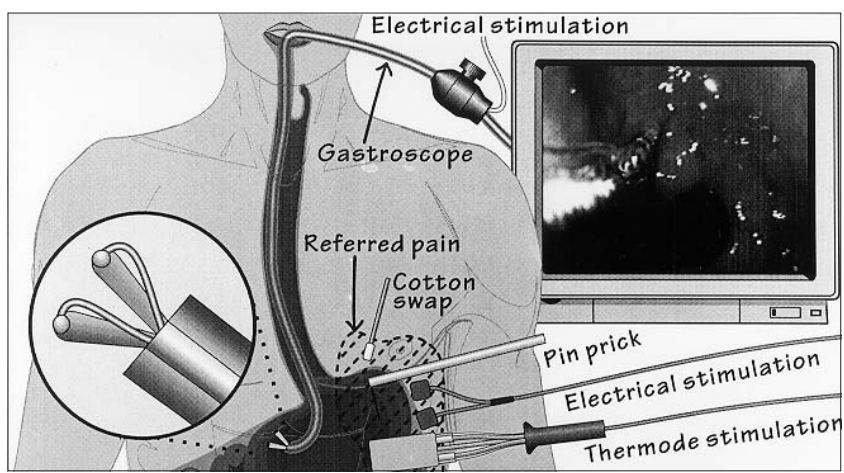

Figure 1) Schematic drawing of the experimental setup for determining pain threshold and referred pain area. During gastroscopy, pain is evoked in the prepyloric area of the stomach by electrical stimuli via the forceps. The procedure is followed on a video screen, which allows correct positioning of the forceps during the experiment. Sensitivity to electrical, heat, touch and pinprick stimuli was determined in the referred pain area and in a control area on the chest

same computer-controlled electrical stimulator described above for the gastric stimuli was used. First, the cutaneous PDTs to single and repeated burst electrical stimuli were found in both areas. To determine the cutaneous S-R function, the stimulus intensity was scored for increasing repeated electrical burst stimuli using the VAS. The intensities of the electrical stimuli were $0.8,1.2,1.4$ and $1.6 \times$ PDT. In experimental pain research, the S-R curves have been shown to be valuable because they can assess general sensitivity changes and changes in central gain to increasing nociceptive input (12). Accordingly, the S-R curves are a sensible measure for testing analgesics in response to experimental pain stimuli, and they make it possible to evaluate both shifts in parallel and shifts in slope. These two features express different aspects of analgesic action. Finally, the S-R curves include a series of measurements with increasing stimulus intensities, which is statistically more consistent than pain thresholds including only one value.

\section{Thermal stimuli}

The sensitivity to contact heat was tested in the two areas with a $4 \mathrm{~cm}^{2}$ thermode consisting of series- coupled Peltier elements (Somedic AB, Stockholm, Sweden). A constant temperature pulse of $46^{\circ} \mathrm{C}$ was applied for $5 \mathrm{~s}$, and the pain intensity was rated on the VAS immediately after the stimulus.

\section{Touch and pinprick}

Sensation to touch was determined using a gentle cotton swab of the skin. For pinprick, a von Frey hair with a bending force of $6.6 \mathrm{~g}$ (SenseLab, Somedic AB, Stockholm, Sweden) was pressed against the skin until it was bent. The cotton swab and pinprick stimulations were given to the two skin areas consecutively, and subjects were asked whether they felt any difference between the two areas. 


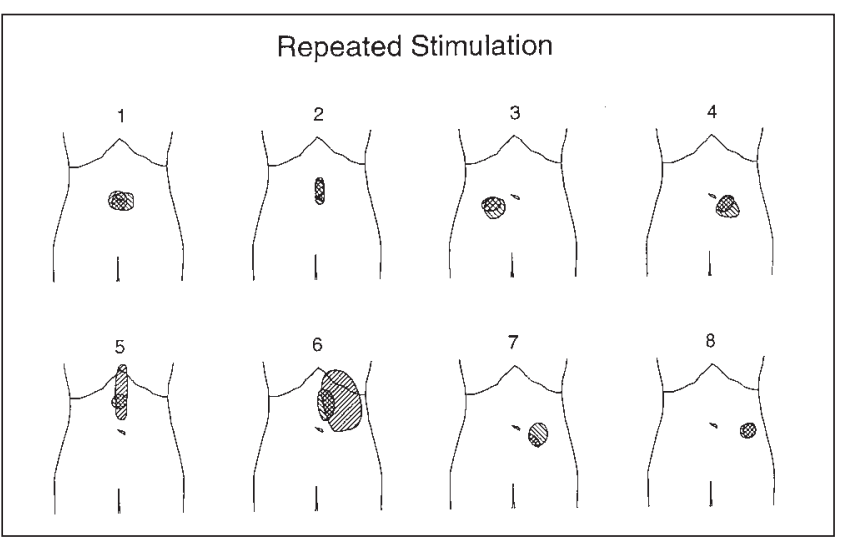

Figure 2) Location of pain referral in eight subjects during repeated burst stimuli in the prepyloric region from the first $(/ / / /)$ and second (III) sessions, separated by four months

\section{Statistical analysis}

Nonparametric methods were used for analysis. Median and range values are given. For calculation of the relative referred pain areas, the mean of the largest and smallest diameter perpendicular to each other on the drawings was used. Wilcoxon's rank sum test was used for paired comparisons, and for several related samples, Friedmans two-way ANOVA was chosen. In the correlations for the S-R functions, Spearman's test was used.

\section{RESULTS}

For all subjects, pain responses to the different stimulus configurations were similar to those experienced in the previous experiment (4). The pain was described as unpleasant, dull and colic-like in sensation. No cardiovascular abnormalities were observed, and no subjects had pain or any other complaints after the study. In one subject there were technical problems with the cutaneous stimulation electrodes, and these data were omitted from the analysis. In another subject the VAS ratings to heat stimuli were omitted because there were secretion problems during the procedure, and the experiment was not completed.

\section{Pain elicited in the prepyloric area}

The current intensities to repeated burst stimuli at PDT were $5.7 \mathrm{~mA}$ (range 2 to $14 \mathrm{~mA}$ ), $6.0 \mathrm{~mA}$ (range 4 to $12 \mathrm{~mA}$ ), 5.5 $\mathrm{mA}$ (range 3.5 to $12 \mathrm{~mA}$ ) and $5.0 \mathrm{~mA}$ (range 2.5 to $8 \mathrm{~mA}$ ) in positions 1 to 4 , respectively. No difference among these thresholds was found ( $\mathrm{P}=0.18$, Friedman's ANOVA). The referred pain corresponding to the four locations showed only minor variations. The location of the area following stimuli in one of the four positions changed to another, adjacent location in five subjects, but the remaining three stimuli resulted in referred pain in the same areas. In three subjects, all four stimuli were felt in exactly the same areas.

The location of the referred pain to repeated burst stimuli was reproducible compared with the experiment done four months previously (Figure 2). The relative area (arbitrary units) of the referred pain was 41.4 (range 12.6 to 362.9 ) at the first session and 44.2 (range 33.2 to 314.0 ) in the present experiment $(\mathrm{P}=0.4$, Wilcoxon's rank sum test). In some persons, however (subjects 5,6 and 7 in Figure 2) a difference in the size of the areas was observed. The cutaneous referred pain area following visceral nociceptive stimuli is by nature diffuse and can be difficult for some subjects to localize precisely. Therefore, the difficulties in drawing the exact area probably explain the difference from session to session in these subjects. The difference in areas, however, did not influence the cutaneous sensitivity measurements in these subjects because the area where the electrodes and thermode were placed was included in the area pointed out by the subjects during stimulation of the stomach. Thus, the subsequent somatosensory experiment could be conducted in all subjects.

\section{Sensibility testing in the referred pain areas}

The results from the cutaneous sensibility tests during continuous gastric stimulation are shown in Table 1. Before visceral stimulation, the heat intensity obtained within the area of referred pain was significantly lower than the intensity in the control area ( $\mathrm{P}=0.028$, Wilcoxon's rank sum test) due to the difference in sensitivity in the two areas (receptor density etc); therefore, the relative values (the difference in VAS ratings between baseline and subsequent measurements) were used for statistical testing.

The current intensities sufficient to reach PDTs at the area of referred pain and the control area were similar, and no differences were seen during gastric pain stimulus. For the S-R functions there was a significant correlation between the VAS scores obtained before and during the gastric pain stimulus ( $\mathrm{P}=0.001$, referred pain area; $\mathrm{P}=0.012$, control area; Spearman's test). This means that no effects on the S-R functions were seen.

When the differences of baseline VAS ratings to heat were compared with those obtained during gastric pain, a significant increase in the ratings was found in the referred pain area versus the control area $(\mathrm{P}=0.02$, Wilcoxon's rank sum test $)$ indicating cutaneous hyperalgesia.

For cotton swab application, one subject reported increased and another subject reported decreased sensation in the referred pain area compared with the control area, whereas the remaining six reported no changes. For pinprick, one subject reported hypoalgesia in the referred pain area, whereas the remaining subjects reported no changes.

\section{DISCUSSION}

The model for experimental pain stimulation of the prepyloric region of the stomach was shown to be reliable in that the area and location of referred pain were comparable with the results obtained four months earlier. The pain thresholds to repeated burst stimuli and the location of referred pain to stimulation were similar for the four adjacent prepyloric areas. During continuous visceral pain stimulation, cutaneous hyperalgesia to heat was observed, but no systematic changes were seen in sensation to electrocutaneous, touch or pinprick 
TABLE 1

Pain detection threshold (PDT) for electrical burst stimuli (single or repeated) and pain intensity of heat (46 $\mathrm{C}$ for $5 \mathrm{~s}$ ) on a visual analogue scale (VAS) in the referred pain area (inside) and a control area on the chest (outside).

PDT for single burst electrical stimuli (mA)
PDT for repeated burst electrical stimuli $(\mathrm{mA})$

\begin{tabular}{lcccccc} 
Timing of Strikes & Inside & Outside & Inside & Outside & Inside & Outside \\
\hline Before & $2.5(1.5-4.8)$ & $2.0(1.3-5.5)$ & $2.0(1.5-4.0)$ & $1.8(1.5-6.0)$ & $3.2(2.5-5.4)$ & $4.8(3.9-6.9)$ \\
During & $2.0(1.0-4.0)$ & $1.5(0.7-5.5)$ & $2.0(0.8-4.0)$ & $2.0(0.8-3.5)$ & $4.6(3.6-6.6)^{*}$ & $5.6(3.3-6.4)$ \\
After & $4.5(1.5-6.0)$ & $3.0(1.5-6.0)$ & $3.8(2.0-5.0)$ & $3.5(1.5-4.0)$ & $4.7(3.5-7.2)$ & $5.4(4.2-6.3)$ \\
\hline
\end{tabular}

Stimuli were applied before, during and after experimental gastric pain elicited by continuous electrical stimuli of the prepyloric region. Data are median (range). ${ }^{*} P=0.02$ comparing the pain intensity in the skin before the experiment with that during continuous gastric pain

stimulations. This modality-specific hyperalgesia is most likely a central phenomenon.

\section{Pain evoked from different prepyloric locations}

Few experimental models for eliciting gastric pain in humans exist $(5,14)$. Most previous studies in the human gastrointestinal tract are based on distension (5,15-18), which activates rather large areas of the gut. The clinical situation, however, often mimics more localized and restricted diseases such as peptic ulcer. Although electrical stimuli are nonspecific, the presented model, being able to elicit pain in all regions of the stomach, has many advantages. The pain thresholds differ in the various regions of the stomach (4), which may reflect different densities of the nociceptors as seen in the large intestine $(19,20)$. In the prepyloric region, however, the pain thresholds were similar in the four positions. Because the model is marginally sensitive to changes in location of stimulation, the technique may be suitable in the study of sensibility changes related to pathological lesions in this region. Thus, the model may be used in the study of pain thresholds in areas of localized inflammation in comparison with neighbouring areas, such as in peptic ulcer disease.

No detailed landmarks are available in the prepyloric region; thus, the stimulation could not be delivered in exactly the same area of the stomach in the experiment as in the previous session. The little variation in referred pain localization at the four prepyloric regions allowed us to stimulate the skin in the expected referred pain area in all subjects before eliciting any gastric pain, thus increasing the validity of the experiment. Furthermore, the similarity of pain referral at the two sessions may be important in future studies where central mechanisms and somatosensory changes following visceral pain are studied.

\section{Sensibility in the referred pain area}

Hyperalgesia, allodynia and other changes in cutaneous sensibility in the area of referred visceral pain have been reported in clinical $(5,8-10,20)$ and animal $(5,21)$ studies. There are, however, only a few studies, and cutaneous sensitivity has not always been systematically assessed. In clinical studies $(8,9,22)$, cutaneous as well as muscle hyperalgesia was seen in patients with calculosis of the upper urinary tract, with normalization of the sensory changes after stone elimination. These findings give support for neuroplastic changes triggered by afferent visceral inputs. Clinical studies can, however, be difficult to control, and many confounding factors exist, especially with respect to individual psychosocial factors. Most bias can be eliminated in experimental studies. In animal studies, viscerosomatic convergence with an increase in the cutaneous receptive fields of spinal neurons has been demonstrated following noxious stimuli (5-7,19,23-25). This supports the clinical observations, although different results have been obtained with respect to facilitation or inhibition of excitability. Thus, in the studies by Laird et al (7) and Ness and Gebhart $(23,25)$, noxious stimulation of visceral afferents either inhibited or had no effect on somatic reflexes. In the study by Cervero et al (6), hyperexcitability of viscerosomatic dorsal horn neurons was found following gall bladder distension. This further emphasizes the need for further basic studies addressing central mechanisms and referred pain phenomena. The present proposed model may be a tool for such investigations.

In the present study, only hyperalgesia to heat was seen, whereas the sensations to electrical stimuli, touch and pinprick were unchanged. Cutaneous contact heat predominantly activates type I mechano-heat sensitive A fibre nociceptors (26). However, the electrical skin stimuli are nonspecific, bypassing the receptors and activating most afferents. The electrical field is strongest closest to the electrodes and decreases in strength as the radial distance away from the dipole increases. Because the thick afferents are depolarized by less current than the thin afferents, we expect a differentiated population of fibres to be activated as the distance away from the electrode location increases. This difference in peripheral input may influence our findings. Thus visceral pain evoked by continuous electrical stimulation may induce a transient, modality-specific hyperexcitability of the local dorsal horn neurons. This modality-specific hyperalgesia is also seen in secondary hyperalgesia to cutaneous injuries (27). Although local reflexes involving the excitability of the dorsal horn neurons may be important, higher centres mediating, for example, selective descending inhibitory control $(11,28)$ may also interact with the neurophysiological mechanisms. Accordingly, animal experiments have shown that any thalamic neuron may respond to many viscera, either by excita- 
tion or by inhibition in its somatic receptive field (29). Hypothetically, descending inhibitory control systems may, therefore, selectively affect different dorsal horn neuron pools, which may respond more or less to specific afferent inflow. This may also explain the dissimilar findings for the heat, electrical and mechanical stimuli. Modality-specific sensitivity changes in the referred pain area have also been seen following experimental muscle pain, although no clear consensus on the type of sensibility changes exists (30). During muscle stimulation, hyperalgesia has been reported to electrical stimuli of the skin, whereas hypoalgesia to radiant heat stimuli was found (11). Hypoalgesia to pinching and pricking have also been described in the referred area after muscle stimulation $(11,31)$. Because, for example, descending inhibitory control for the referred pain area differs when deep and superficial input are compared (32), muscle and viscera may also differ in many aspects. Most importantly, the enteric nervous system is probably phylogenetically different and in many ways autonomic with respect to basic functions, whereas the muscles, being involved in protective reflexes during pain stimuli, for example, are more closely coupled to the central nervous system. Therefore, the neurophysiological mechanisms in visceral pain and pain following activation of muscle tissue may differ, and differences in the sensation of the referred pain area should be expected.

\section{CONCLUSIONS}

Electrical pain stimuli in the prepyloric region of the stomach is a reliable model to study visceral referred pain. The model permits studies of central mechanisms related to referred pain. Modality-specific sensory changes are found in the referred pain areas, and the method provides possibilities for basic physiological, clinical and pharmacological studies.

ACKNOWLEDGEMENTS: The study was supported by Grosserer LF Foghts Fond, Lægernes Forsikringsforening af 1891 and The Danish National Research Foundation. Lis Meyer, Aalborg Hospital, and Jens H Jensen, Aalborg University, are acknowledged for technical assistance.

\section{REFERENCES}

1. Bochus HL. Abdominal pain. In: Berk JE, ed. Gastroenterology. Philadelphia: WB Saunders, 1985:22-47.

2. Haubrich WS. Abdominal pain. In: Haubrich WS, Schaffner F, Berk JE, eds. Gastroenterology, vol 1. Philadelphia: WB Saunders, 1995:11-29

3. Lam SK, Hui WM, Ching CK. Peptic ulcer disease. In: Haubrich WS, Schafner F, Berk JE, eds. Brokus Gastroenterology. Philadelphia: WB Saunders, 1995:700-48.

4. Drewes AM, Arendt-Nielsen L, Jensen JH, et al. Experimental pain in the stomach: a model based on electrical stimulation guided by gastroscopy. Gut 1997;41:753-7.

5. Ness TJ, Gebhart GF. Visceral pain: a review of experimental studies. Pain 1990;41:167-234.

6. Cervero F, Laird JMA, Pozo MA. Selective changes of receptive field properties of spinal nociceptive neurones induced by noxious visceral stimulation in the cat. Pain $1992 ; 51: 335-42$
7. Laird JMA, de la Rubia PG, Cervero F. Excitability changes of somatic and viscero-somatic nociceptive reflexes in the decerebrate-spinal rabbit: role of NMDA receptors. J Physiol 1995;489:545-55.

8. Vecchiet L, Giamberardino MA, Dragani L, Albe-Fessard D. Pain from renal/ureteral calculosis: evaluation of sensory thresholds in the lumbar area. Pain 1989;36:289-95.

9. Giamberardino MA, Bigontina P, Martegiani C, Vecchiet L. Effects of extracorporal shock-wave lithotripsy on referred hyperalgesia from renal/ureteral calculosis. Pain 1994;56:77-83.

10. Head H. On disturbances of sensation, with special reference to the pain of visceral diseases. Brain 1893;16:1-133.

11. Graven-Nielsen T, Arendt-Nielsen L, Svensson P, Jensen TS. Stimulus-response functions in areas with experimentally induced referred muscle pain - a psychophysical study. Brain Res 1997;744:121-8.

12. Arendt-Nielsen L. Induction and assessment of experimental pain from human skin, muscle, and viscera. In: Jensen TS, Turner JA, Wiesenfeld-Hallin Z, eds. Proceedings of the 8th World Congress of Pain, Progress in Pain Research and Management, vol 8. Seattle: IASP Press, 1997:393-425.

13. Laursen RJ, Graven-Nielsen T, Jensen TS, Arendt-Nielsen L. Referred pain is dependent on sensory input from the periphery-a psychophysical study. Eur J Pain ( In press).

14. Gebhart GF, Meller ST, Euchner-Wamser I, Sengupta JN. Modelling visceral pain. In: Vecchiet L, Albe-Fessard D, Lindblom U, Giamberardino MA, eds. New Trends in Referred Pain and Hyperalgesia. Amsterdam: Elsevier, 1993:129-48.

15. Lembo T, Munakata J, Mertz H, et al. Evidence for the hypersensitivity of lumbar splanchnic afferents in irritable bowel syndrome. Gastroenterology 1994;107:1686-96.

16. Mertz H, Naliboff B, Munakata J, Niazi N, Mayer EA. Altered rectal perception is a biological marker of patients with irritable bowel syndrome. Gastroenterology 1995;109:40-52.

17. Munakata J, Naliboff B, et al. Repetitive sigmoid stimulation induces rectal hyperalgesia in patients with irritable bowel syndrome. Gastroenterology 1997;112:55-63.

18. Klatt S, Pieramico O, Guethner C, Glasbrenner B, Beckh K, Adler G. Gastric hypersensitivity in nonulcer dyspepsia: an inconsistent finding. Dig Dis Sci 1997;42:720-3.

19. Cervero F. Visceral pain. In: Dubner R, Gebhart GF, Bond MR, eds. Pain Res Clin Manage, Proceedings of the fifth World Congress on Pain, vol 3. Amsterdam: Elsevier, 1988:216-26.

20. Jänig W, Haupt-Schade P, Kohler W. Afferent innervation of the colon: the neurophysiological basis for visceral sensation and pain. In: Mayer EA, Raybould HE, eds. Basic and Clinical Aspects of Chronic Abdominal Pain. Amsterdam: Elsevier, 1993:71-86.

21. Giamberardino MA, Rampin O, Laplace JP, Vecchiet L, Albe-Fessard D. Muscular hyperalgesia and hypoalgesia after stimulation of the ureter in rats. Neurosci Lett 1988;87:29-34.

22. Vecchiet L, Giamberardino MA, Bigontina P. Referred pain from viscera. When the symptom persists despite the extinction of the visceral focus. In: Sicutero, ed. Advances in Pain Research and Therapy, vol 20. New York: Raven Press, 1992:101-10.

23. Ness TJ, Gebhart GF. Characterization of neurons responsive to noxious colorectal distension in the T13-L2 spinal cord of the rat. J Neurophysiology 1988;60:1419-38.

24. Ness TJ, Gebhart GF. Interactions between visceral and cutaneous nociception in the rat. Noxious cutaneous stimuli inhibit visceral nociceptive neurons and reflexes. J of Neurophysiol 1991;66:20-8.

25. Ness TJ, Gebhart GF. Interactions between visceral and cutaneous nociception in the rat. II. Noxious visceral stimuli inhibit cutaneous nociceptive neurons and reflexes. J Neurophysiol 1991;66:29-39.

26. Treede R D, Meyer RA, Raja SN, Campbell JN. Evidence for two different heat transduction mechanisms in nociceptive primary afferents innervation monkey skin. J Physiol 1995;483:747-58.

27. Torebjörk HE, Lundberg LER, LaMotte RH. Central changes 
in processing of mechanoreceptive input in capsaicin-induced secondary hyperalgesia in humans. J Physiol 1992;448:765-80.

28. Drossman DA. Chronic functional abdominal pain. Am J Gastroenterol 1996;91:2270-81.

29. Apkarian AV, Brüggemann J, Shi T, Airapetian LR. A thalamic model for true and referred visceral pain. In: Gebhart GF, ed. Visceral Pain. Seattle: IASP Press, 1995:217-59.

30. Graven-Nielsen T. "Sensory manifestations and sensory- motor interactions during experimental muscle pain in man". $\mathrm{PhD}$ dissertation. Aalborg University, 1997.

31. Feinstein B, Langton JNK, Jameson RM, Schiller F. Experiments on pain referred from deep tissues. J Bone Joint Surg 1954;36:981-97.

32. Yu X M, Hua M, Mense S. The effects of intracerebroventricular injection of naloxone, phentolamine and methysergide on the transmission of nociceptive signals in rat dorsal horn neurons with convergent cutaneous-deep input. Neuroscience 1991;44:715-23. 


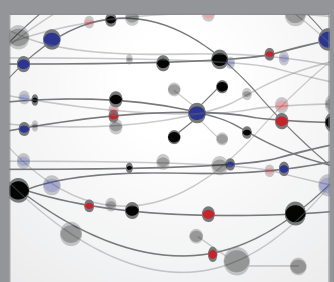

The Scientific World Journal
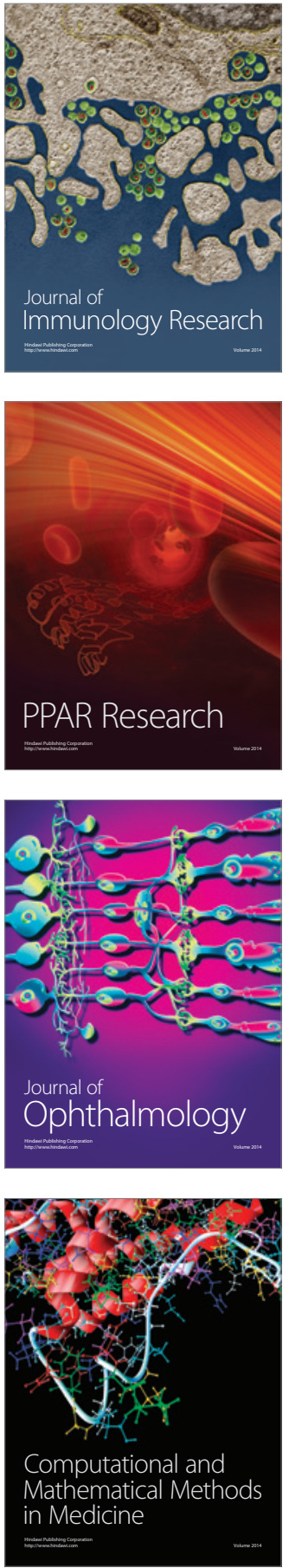

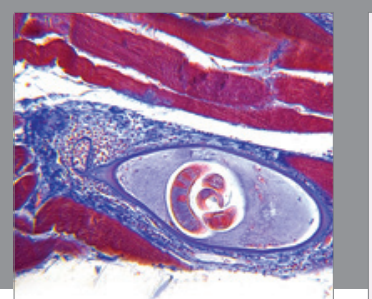

Gastroenterology Research and Practice

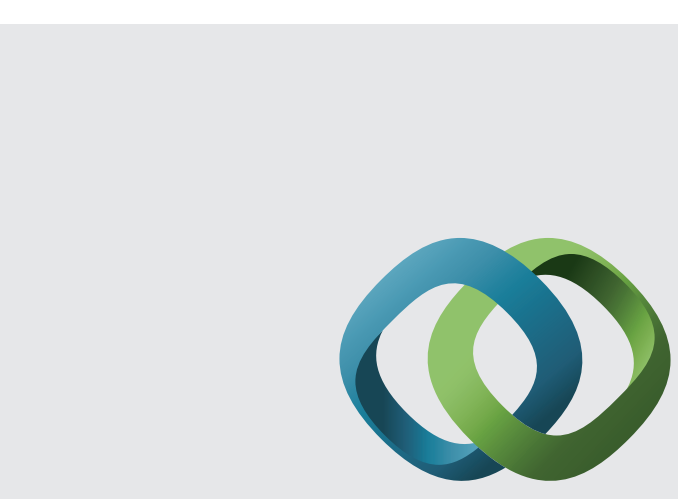

\section{Hindawi}

Submit your manuscripts at

http://www.hindawi.com
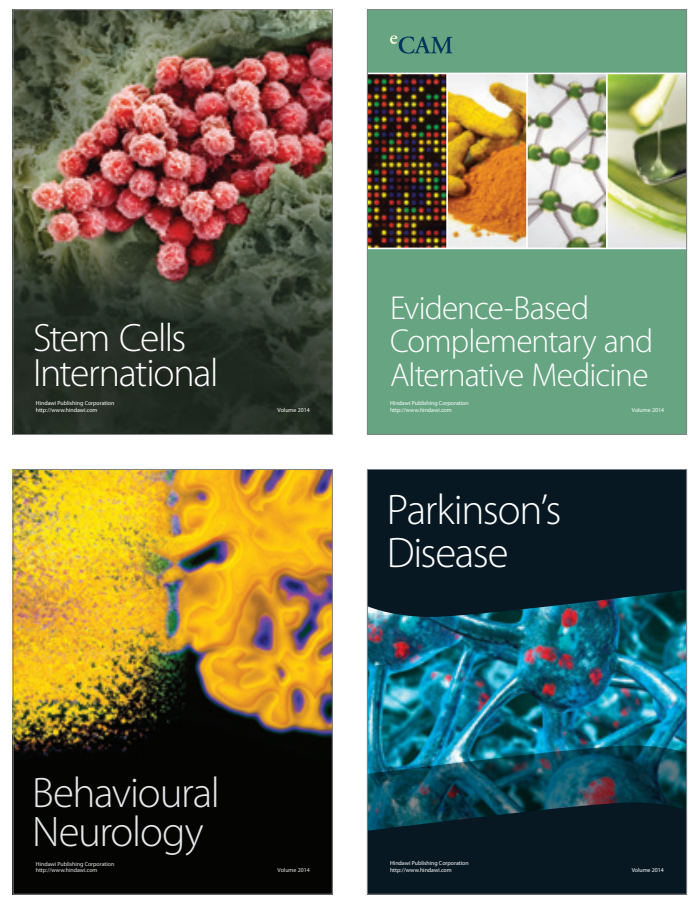
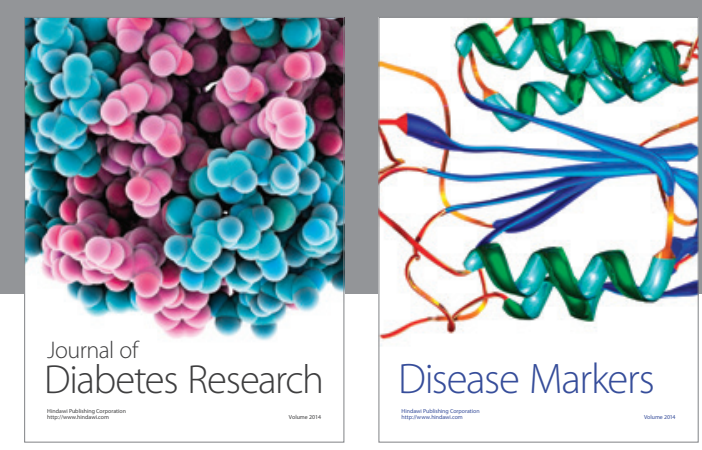

Disease Markers
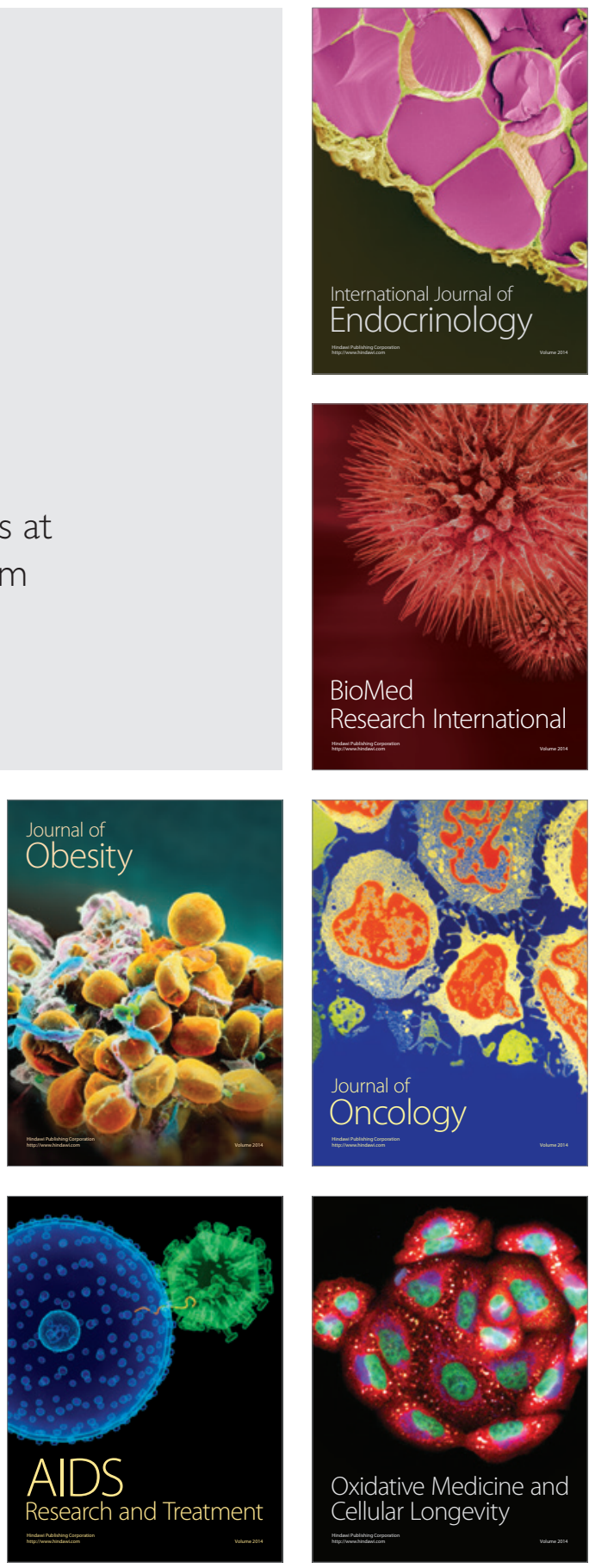